\title{
Identification of QTL Conditioning Resistance to White Mold in Snap Bean
}

\author{
Phillip N. Miklas ${ }^{1}$ and Richard Delorme \\ U.S. Department of Agriculture, Agricultural Research Service, Vegetable and Forage Crop Research \\ Unit, 24106 North Bunn Road, Prosser, WA 99350 \\ Ron Riley \\ Syngenta Seed Company Inc., Nampa Research Center, Nampa, ID 83687 \\ ADDITIONAL INDEX wORDS. Phaseolus vulgaris, Sclerotinia sclerotiorum, RAPD markers
}

\begin{abstract}
Host resistance is an important component of integrated disease management strategies for control of Sclerotinia white mold disease in snap bean (Phaseolus vulgaris L.). Few resistant snap bean cultivars have been bred, however, because genetic resistance to white mold is not well understood. This study was conducted to examine inheritance and identify quantitative trait loci (QTL) for white mold resistance in an $F_{5: 7}$ recombinant inbred line (RIL) population ('Benton'/NY6020-4). 'Benton' snap bean is susceptible to white mold. Snap bean germplasm line NY6020-4 has partial resistance. The parents and $77 \mathrm{~F}_{5: 7}$ RILs were tested for resistance to white mold across four greenhouse and two field environments. Moderately high heritability estimates were observed for straw test $(0.73)$ and field $(0.62)$ reaction. Selective mapping of 27 random amplified polymorphic DNA (RAPD) markers detected two QTL conditioning resistance to white mold on linkage groups B6 and B8 of the core map. The B6 QTL explained 12\% and B8 QTL $38 \%$ of the variation for disease reaction in the straw test. The two QTL explained $13 \%$ and $26 \%$ disease reaction in the field, respectively. Favorable alleles for all the QTL were derived from NY6020-4, except for the B6 QTL conditioning resistance to white mold in the field, which was derived from 'Benton'. The B6 QTL was located near the Ur-4 rust resistance gene, and was associated with canopy height and lodging traits that condition disease avoidance. The B8 QTL was associated with increased internode length, an undesirable trait in snap bean, which may hamper use of white mold resistance derived from NY6020-4.
\end{abstract}

White mold caused by the fungal pathogen Sclerotinia sclerotiorum Lib. de Bary is a major disease limiting snap bean (Phaseolus vulgaris L.) production worldwide. It is also one of the most difficult diseases to control. Breeders are currently working toward development of resistant cultivars as a component of integrated disease management strategies. A few novel sources of resistance to white mold exist in common bean, and there have been a few dry bean and snap bean lines bred with improved resistance (Kolkman and Kelly, 2000; Lyons et al., 1987; Miklas et al., 1999; Petzodlt and Dickson, 1996; Steadman et al., 2001). The partial resistance characterized to date comprises both physiological and avoidance mechanisms, which are quantitatively inherited, with low to moderate heritability (Dickson et al., 1982; Fuller et al., 1984; Kolkman and Kelly, 2002; Miklas and Grafton, 1992; Miklas et al., 2001; Park et al., 2001).

Recent quantitative trait loci (QTL) analyses of resistance to white mold in dry bean RIL populations has led to the identification and mapping of major QTL contributing to resistance. A QTL from Andean cultivar Jatu Rong (synonymous with G 122), identified on linkage group B7 of the core map (Freyre et al., 1998), explained 38\% $\left(R^{2}\right)$ of the variation in greenhouse reaction and 26\% in the field (Miklas et al., 2001). A second QTL from $\mathrm{G} 122$, located on linkage group $\mathrm{B} 1$, conditioned disease avoidance in the field $\left(R^{2}=18 \%\right)$. This QTL was attributable to determinate bush growth habit controlled by the fin gene. Conversely, Kolkman and Kelly (2002) observed that indeterminate

Received for publication 5 Nov. 2002. Accepted for publication 13 Mar. 2003. This report summarizes, in part, a Cooperative Research and Development Agreemen 58-3K95-9-715 between the U.S. Dept. of Agriculture, Agricultural Research Service, and Syngenta Seed Company Inc. Use of a company name or product by the USDA does not imply approval or recommendation of the product to the exclusion of others that also may be suitable.

1To whom reprint requests should be addressed; e-mail pmiklas@pars.ars.usda.gov. upright vine growth habit was associated with less disease in a Middle American navy bean cross. These contrasting results are attributable, in part, to differences in bush growth habit between gene pools (Kolkman and Kelly, 2003). Traditionally, bush growth habit in the Andean gene pool is associated with more upright and open architecture with less branching versus the Middle American gene pool where it is associated with more branching, less upright architecture, and a denser canopy. Determinacy also appears to be conditioned by different genes, fin on B1 in the Andean gene pool, and an unnamed locus on B7 in the Middle American gene pool (Kolkman and Kelly, 2003).

Quantitative trait loci from PC 50, another Andean dry bean cultivar exhibiting partial resistance to white mold, were identified on linkage groups B7 and B8 (Park et al., 2001). The QTL conditioned white mold resistance in the greenhouse $\left[R^{2}=9 \%\right.$ (B7) and $R^{2}=24 \%$ (B8)] and field $\left[R^{2}=16(\mathrm{~B} 7)\right.$ and $R^{2}=9 \%$ (B8)]. The two QTL also influenced plant height $\left[R^{2}=15 \%\right.$ (B7) and $R^{2}=10 \%$ (B8)]. Two QTL imparting field resistance, derived from 'Bunsi' navy bean, were identified on B2 $\left(R^{2}=12 \%\right)$ and B7 $\left(R^{2}=17 \%\right)$ (Kolkman and Kelly, 2003). Quantitative trait loci from G 122 and PC 50 map to the same genomic region of B7 near an apparent cluster of genes conditioning resistance to different pathogens; whereas, the Bunsi-derived QTL is located at the opposite end of B7 (Kelly et al., 2003).

Resistance to white mold is generally lacking in snap bean cultivars, and the inheritance is not fully understood. Lyons et al. (1987) used recurrent selection to obtain snap bean germplasm with partial resistance to white mold. The inheritance of resistance for one such line NY5262 was moderately high indicating presence of major genes that could be transferred into pinto bean by backcross (Miklas and Grafton, 1992). NY6020-4 was independently identified by the straw test in the Prosser, Wash. and Nampa, Idaho, greenhouses as having the highest level of 
resistance among a recent group of Cornell Univ. snap bean lines bred specifically for a high level of white mold resistance (Petzoldt and Dickson, 1996). NY6020-4 and a sister line NY6020-5 also expressed resistance in the field (Steadman et al., 2001).

The objectives of this study were to examine inheritance and identify QTL for resistance to white mold in a snap bean population derived from a cross between NY6020-4 and the susceptible snap bean 'Benton'.

\section{Materials and Methods}

Plant materials and Population Development. NY6020-4 snap bean with determinate bush growth habit was bred for a high level of resistance to white mold using recurrent selection (Lyons et al., 1987). It has pale, short oval pods. Also NY60204 lodges, has narrow adaptation, and is late maturing. 'Benton' is a processing snap bean with determinate bush growth habit, round pods with acceptable length and color, heat tolerance, wide adaptation and mid-season maturity, but is highly susceptible to white mold. A population of $77 \mathrm{~F}_{5}$-derived $\mathrm{F}_{7}$ recombinant inbred lines (RILs) from a cross between 'Benton' and NY6020-4 was generated using the single seed descent method.

Greenhouse TESTS. The straw test described by Petzoldt and Dickson (1996) was used to screen the RIL population and parents for white mold resistance in four separate greenhouse environments. Straw Tests 1 (October 1999) and 2 (December 1999) were conducted at Prosser, Wash., and Straw Tests 3 (January 2000) and 4 (March 2000) were conducted at Nampa, Idaho. An individual plant of each genotype represented a replicate, and the replications were randomized in complete blocks. Six replications were included in the Prosser and five in the Nampa tests. For all tests the greenhouse environment was maintained at 18 ${ }^{\circ} \mathrm{C} /$ night to $25^{\circ} \mathrm{C} /$ day with a $14 \mathrm{~h}$ daylength provided by sunlight and supplemental lighting. Plants were watered and fertilized for normal growth. The S. sclerotiorum culture T001.1, hyphal-tip isolated from a sclerotia collected from 'Newport' navy bean in Quincy, WA in 1996, was the source of inoculum for the Prosser tests. The isolate CoSyn01 used for the Nampa tests was obtained from dry bean culls from Colorado. The intact main stem (freshly cut above or below the fifth node) was fitted with a plastic straw containing an agar plug of mycelium $\approx 28 \mathrm{~d}$ after planting (DAP) (Petzoldt and Dickson, 1996). Mycelium germinated from a single sclerotium placed on a PDA plate was subcultured to prepare plates of growing mycelium for the inoculations. The entire $15 \times 100 \mathrm{~mm}$ petri plate of growing mycelium was used as inoculum once the mycelium reached the periphery of the plate, $\approx 3 \mathrm{~d}$ after subculturing. Eight days after inoculation, reaction to white mold was scored from 1 to 9 , where $1=$ no symptoms, 2 = invasion of the stem past the site of inoculation but not to the first node, 3 = invasion of the stem to the first node, $4=$ invasion of the internode slightly past the first node, $5=$ invasion to the middle of the internode, $6=$ invasion to the second node, $7=$ invasion slightly past the 2 nd node, $8=$ invasion to the middle of the second internode and beyond, and $9=$ total plant collapse (Petzoldt and Dickson, 1996).

An association of longer internode length with white mold resistance in the field was observed subsequent to the tests conducted above. Thus, to examine the potential effect of internode length on straw test reaction, the length $(\mathrm{mm})$ of the first internode (between the cotyledon and primary leaf nodes) was recorded for the RILs and parents in a separate non-inoculated greenhouse test conducted at Nampa in April 2002. A randomized complete block design with six replications (one plant per replicate) was used. Length $(\mathrm{mm})$ of the first internode was measured 18 DAP.

FIELD TESTS. Resistance of the RILs and parents to S. sclerotiorum in the field was examined across two environments. The tests, planted 21 June 2000 and 19 June 2001 were conducted at Paterson, Washington. The field plot at the USDA-ARS Cropping Systems Research Farm at Paterson has a history of uniform $S$. sclerotiorum disease in potato (Solanum tuberosum L.) and pea (Pisum sativum L.), and more recently has been used successfully to differentiate common bean lines for reaction to white mold (Miklas, 2001; Miklas et al., 2001). The soil is a Quincy sandy loam (mixed, mesic Typic Torripsamments).

For each field test, a randomized complete-block design with three replications was used. A plot consisted of one row $3 \mathrm{~m}$ long. Each plot was bordered on one side by the susceptible pinto bean 'Burke' (Hang et al., 1998). Plot and border rows were spaced $0.56 \mathrm{~m}$ apart. Planting density was 234,848 seeds/ha. To promote white mold disease, $\approx 6.3 \mathrm{~mm}$ of water was applied by overhead center-pivot irrigation on a daily basis from the onset of flowering to late pod-fill. To maintain vigorous plant growth, nitrogen was foliar applied by chemigation at a rate of $22 \mathrm{~kg} \cdot \mathrm{ha}^{-1}$ on a weekly basis for eight weeks from the early seedling growth stage $(\approx 18$ DAP) to mid pod-fill ( $\approx 74$ DAP).

Disease reaction was scored from 1 to 9 based on combined incidence and severity of infection at physiological maturity, where $1=$ no diseased plants and $9=80 \%$ to $100 \%$ diseased plants and/or $60 \%$ to $100 \%$ infected tissue (Miklas et al., 2001). Traits associated with disease avoidance were also measured. Canopy height $(\mathrm{mm})$ was measured at mid pod fill and lodging ( 1 to 9 ; where $1=$ no lodging and $9=>90 \%$ lodged) was scored at physiological maturity. To determine phenotypic associations among traits, simple correlation coefficients were computed between all the trait means combined across environments using PROC CORR (SAS, 1987).

INHERITANCE STATISTICS. Analysis of variance for each trait was performed by PROC GLM (SAS, 1987). Error mean squares for the separate analyses of variance for the four straw tests, and the two field tests, were homogeneous based on Bartlett's tests (Steel and Torrie, 1980); therefore, combined analyses of variance were conducted to obtain heritability $\left(\mathrm{h}^{2}\right)$ estimates for disease score on a progeny mean basis (Fehr, 1987). The $h^{2}$ estimates for canopy height and lodging were likewise based upon the combined analysis of variance. Exact $90 \%$ confidence intervals were calculated for $\mathrm{h}^{2}$ according to Knapp et al. (1985). Frequency distributions of the RIL means for the different traits were tested for normality using the Shapiro and Wilk test statistic $W$ (PROC Univariate, SAS, 1987). A probability of $P<0.001$ was used to indicate lack of fit.

Selective MAPPING. Equal amounts of DNA, from the seven most resistant and six most susceptible RILs as determined by average disease reaction across all four straw tests and the 2000 field test, were used to form resistant (R-bulk) and susceptible (S-bulk) DNA bulk samples, respectively. The R- and S-bulks were initially screened against 391 decamer primers (Operon Technologies, Alameda, Calif.) for presence of RAPD markers. All RAPD markers observed between the bulks were assayed across the individuals that comprised the bulks, and the parents as checks. RAPD markers that cosegregated with disease reaction in at least $85 \%$ of the individuals comprising the DNA bulks were subsequently assayed across the entire population of 77 RILs.

A second screening of the bulks for RAPD markers with a different set of 500 decamer primers was conducted in an effort 
to further saturate major QTL regions with additional markers. Only RAPD markers present in the R-bulk and absent in the Sbulk were targeted in the second screening because they provided the best opportunity for application in marker-assisted selection. Similarly, markers that cosegregated with disease reaction among $85 \%$ of the individuals comprising the bulks were assayed across the whole population.

Genetic LinKage MaP. A partial linkage map of the selectively mapped markers was constructed using Mapmaker 3.0 (Lander et al., 1987). A pairwise linkage analysis of the marker data, imposing a minimum LOD score of 3.0 and maximum distance of $30 \mathrm{cM}$, was used to establish the linkage groups. Three-point and multipoint log-likelihood thresholds (LOD) of 2.5 and 2.0, respectively, were used to order the markers within linkage groups with the Order and Ripple commands. Centimorgan distances between linked loci were based upon recombination fractions using the Kosambi (1944) mapping function. The mapping of QTL-linked RAPD markers across the BAT 93/Jalo EEP 558 RIL population was used to anchor partial linkage groups obtained in this study to the core $P$. vulgaris map (Freyre et al., 1998).

The selectively mapped RAPD marker A14.1100 was previously found (Miklas et al., 1993) to be tightly linked with the rust [Uromyces appendiculatus (Pers.:Pers) Unger] resistance gene Up-2 [later renamed Ur-4 (Kelly et al., 1996)]. Therefore, the parents and $77 \mathrm{~F}_{5: 7}$ RILs were inoculated with Race 49 to assess presence or absence of $U r-4$. Rust screening followed the procedure of Miklas et al. (1993).

QTL ANALYSIS. For the partial linkage groups, simple interval mapping (SIM) performed by MQTL (Tinker and Mather, 1995) was used to detect QTL with main effects for resistance in the straw test and field, first internode length, and canopy height and lodging associated with disease avoidance. A significant QTL was declared if the test statistic calculated by MQTL was greater than the significance threshold determined by permutation analyses (1000 permutations) of the data sets for each trait based upon a 5\% experiment-wise error rate (Doerge and Rebai, 1996). Simple composite interval mapping ( $\mathrm{SCIM}$ ) was used to refine the genomic position of a QTL identified by SIM. The $R^{2}$ value for describing the phenotypic variation explained by a significant QTL was calculated as (variance explained)/(total variance). Quantitative trait loci with main effects (expressed across environments) were targeted because they provide the best opportunity for use in marker-assisted selection compared to the less desirable simple-effect QTL that are only expressed in single environments.

The additive effect of QTL and agronomic traits on disease score in the field was modeled by multiple stepwise regression (PROC REG, SAS, 1987). A significance level of $15 \%$ was required for a trait to be included in the model.

\section{Results}

GreENHOUSE TESTS. The two parents differed significantly for reaction to white mold in the straw test with NY6020-4 exhibiting partial resistance and "Benton" susceptibility (Table 1). Mean disease scores of the RILs obtained from the individual straw tests were significantly correlated (average $r=0.43$ ), indicating that the straw test gave repeatable results across greenhouse environments as reported previously (Miklas et al., 2001; Myers et al., 1999). As enabled by homogeneity of error mean-squares only the combined analysis of the four straw tests is reported herein. The frequency distribution of the RILs for mean disease score was normally distributed, such that there was a lack of discrete resistant and susceptible segregation classes (data not shown). The $\mathrm{h}^{2}(0.73)$ for disease score across the straw tests was moderately high.

'Benton', had a short first internode; whereas, NY6020-4 had a much longer first internode (Table 1). Increased first internode length had a similar association with increased resistance to white mold in the straw test and field (Table 2). The frequency distribution of the RILs for first internode length was normally distributed, and the $\mathrm{h}^{2}$ estimate (0.84) for first internode length, although high, was biased upward due to presence of $o^{2} \mathrm{ge}$ in the numerator for the equation: $\mathrm{h}^{2}=o^{2} \mathrm{~g}+{ }^{2} \mathrm{ge} / o^{2} \mathrm{p}$.

FiELD TESTS. As expected, 'Benton' exhibited a susceptible reaction to white mold in the field and NY6020-4 had a partially resistant reaction (Table 1). Although susceptible, 'Benton' had slightly lower canopy height and was less lodged compared to NY6020-4. Increased canopy height and reduced lodging were associated with less disease in the field, as might be expected for such traits known to contribute to disease avoidance (Table

Table 1. Mean, range, and heritability estimates for resistance to white mold in the straw test and field, first internode length, canopy height, and lodging for $77 \mathrm{~F}_{5: 7}$ RILs from a snap bean population 'Benton'/NY6020-4, and means for the parents, tested across multiple environments.

\begin{tabular}{|c|c|c|c|c|}
\hline \multirow[b]{2}{*}{ Trait } & \multicolumn{2}{|c|}{ Parent means } & \multicolumn{2}{|c|}{ Recombinant inbred population } \\
\hline & 'Benton' & NY6020-4 & Mean (range) & $\mathrm{h}^{2} /(90 \% \mathrm{CI})$ \\
\hline Straw test (1-9) & $7.8 \mathrm{a}^{\mathrm{z}}$ & $3.8 \mathrm{~b}$ & $5.9(4.3-8.2)$ & $0.73 /(0.83-0.61)$ \\
\hline Field reaction (1-9) & $5.8 \mathrm{a}$ & $3.4 \mathrm{~b}$ & $4.5(2.5-6.6)$ & $0.62 /(0.73-0.37)$ \\
\hline First internode length $(\mathrm{mm})^{y}$ & $2.6 \mathrm{a}$ & $10.3 \mathrm{~b}$ & $5.3(3.3-8.6)$ & $0.84 /(0.87-0.74)$ \\
\hline Canopy height $(\mathrm{mm})$ & $526 \mathrm{a}$ & $574 \mathrm{~b}$ & $542(438-673)$ & $0.50 /(0.66-0.21)$ \\
\hline Lodging (1-9) & $4.6 \mathrm{a}$ & $7.2 \mathrm{~b}$ & $5.5(2.8-7.3)$ & $0.72 /(0.80-0.52)$ \\
\hline
\end{tabular}

${ }^{2}$ Parental means in a row followed by the same letters were not significantly different at the 5\% probability level (LSD).

y Note that first internode length was measured in only one greenhouse environment; therefore, the $\mathrm{h}^{2}$ estimate may be biased upward.

Table 2. Simple correlation coefficients among white mold (WM) disease score means and agronomic trait means across straw and field tests, in a population of $77 \mathrm{~F}_{5 \cdot 7}$ RILs from the cross 'Benton'/NY6020-4.

\begin{tabular}{|c|c|c|c|c|}
\hline Trait & $\begin{array}{l}\text { WM straw } \\
\text { test (1-9) }\end{array}$ & $\begin{array}{l}\text { 1st Internode } \\
\text { length }\end{array}$ & $\begin{array}{l}\text { WM field } \\
\text { score }\end{array}$ & $\begin{array}{c}\text { Canopy } \\
\text { ht }\end{array}$ \\
\hline 1st Internode (mm) & $-0.45^{* *}$ & & & \\
\hline WM field score (1-9) & NS & $-0.27 *$ & & \\
\hline Canopy height (mm) & NS & NS & $-0.42^{* *}$ & \\
\hline Lodging (1-9) & $-0.43^{* *}$ & $0.29^{*}$ & $0.30^{*}$ & NS \\
\hline
\end{tabular}

Ns,***NNonsignificant or significant at $P=0.05$ or 0.01 , respectively. 


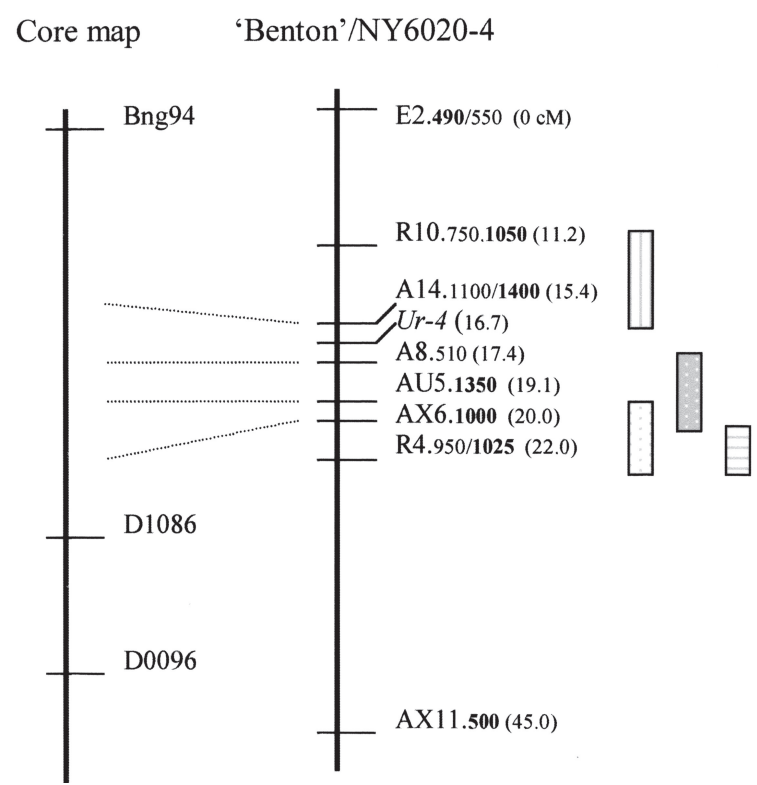

Core map 'Benton'/NY6020-

Fig 1. Depiction of partial linkage groups possessing selectively mapped QTL $(P<0.005)$ conditioning disease reaction to white mold in the straw test, and field, and canopy height, lodging, and first internode length for the 'Benton'/NY6020-4 RIL population; with partial linkage groups co-integrated with the core map BAT 93/ Jalo EEP 558 (Freyre et al., 1998) via RAPD markers amplified in both populations (dotted lines). The bar length represents the most likely position of the QTL as determined by SIM and SCIM analyses in MQTL. For RAPD marker nomenclature: letters and numbers before the period indicate the Operon primer kit and specific decamer; numbers after the period indicate size (bp) of the marker (single and double sizes refer to dominant and codominant RAPD marker alleles, respectively); and sizes in bold type refer to alleles amplified in NY6020-4. The numbers in parentheses refer to the accumulated recombination frequency in centimorgans (cM) (Kosambi, 1944) among markers forming the partial linkage groups. Bng and D designate RFLP markers on the core map. Ur-4 is a rust gene present in 'Benton' conditioning resistance to Race 49.

2). The $\mathrm{h}^{2}$ estimates for disease score in the field, canopy height and lodging were moderately high. The frequency distributions of the RILs for disease reaction and agronomic trait means were normally distributed.
Selective MaPPING AND QTL analysis. Only 27 RAPD markers that met the criteria for selective mapping. Upon mapping these markers, two partial linkage groups were generated, one comprising eight and the other ten RAPD markers (Fig. 1). These

Table 3. Selectively mapped RAPDs spanning the most likely position of QTL exhibiting main effects as detected by SIM and sCIM for resistance to white mold across greenhouse (straw test) and field environments, first internode length as measured in a single greenhouse environment, and canopy height and lodging across field environments for a snapbean population of $77 \mathrm{~F}_{5: 7}$ RILs from the cross 'Benton'/NY6020-4.

\begin{tabular}{|c|c|c|c|c|c|}
\hline \multirow[b]{2}{*}{ Trait } & \multirow[b]{2}{*}{ Marker $^{z}$} & \multirow{2}{*}{$\begin{array}{c}\text { Linkage } \\
\text { group }\end{array}$} & \multirow[b]{2}{*}{$R^{2}(\%)$} & \multicolumn{2}{|c|}{ Means } \\
\hline & & & & 'Benton'y & NY6020-4 \\
\hline \multirow[t]{6}{*}{ Straw test (disease score 1-9) } & AU5.1350 & B6 & 12 & 6.1 & 5.5 \\
\hline & AX6.1000 & B6 & 10 & 6.2 & 5.5 \\
\hline & R4.950/1025 & B6 & 6 & 6.2 & 5.6 \\
\hline & B10.1100 & B8 & 38 & 6.3 & 5.3 \\
\hline & C5.350/400 & B8 & 32 & 6.4 & 5.4 \\
\hline & AW9.1200 & B8 & 35 & 6.4 & 5.4 \\
\hline \multirow[t]{7}{*}{ Field (disease score 1-9) } & A8.510 & B6 & 9 & 3.4 & 4.4 \\
\hline & AU05.1350 & B6 & 10 & 3.4 & 4.4 \\
\hline & AX6.1000 & B6 & 13 & 3.3 & 4.5 \\
\hline & AW9.1200 & B8 & 26 & 4.5 & 3.2 \\
\hline & V14.775 & B8 & 22 & 4.4 & 3.3 \\
\hline & S18.1650 & B8 & 23 & 4.4 & 3.3 \\
\hline & C7.850 & B8 & 22 & 4.4 & 3.3 \\
\hline \multirow[t]{2}{*}{ First internode length (mm) } & AX11.425 & B8 & 23 & 4.6 & 5.9 \\
\hline & B10.1100 & B8 & 26 & 4.7 & 5.8 \\
\hline \multirow[t]{2}{*}{ Canopy height (mm) } & R10.750.1050 & B6 & 20 & 466 & 490 \\
\hline & A14.1100/1400 & B6 & 20 & 468 & 487 \\
\hline \multirow[t]{2}{*}{ Lodging (1-9) } & AX6.1000 & B6 & 15 & 4.4 & 5.7 \\
\hline & R4.950.1025 & B6 & 12 & 4.5 & 5.6 \\
\hline
\end{tabular}

zFor linkage distances between markers see Figs. 1 and 2. The R4.950/1025, C5.350/400, R10.750.1050, and A14.1100/1400 markers are codominant; dominant RAPDs in bold amplified solely in NY6020-4.

y Means of RILs possessing the parental alleles for the QTL-linked marker. 
partial linkage groups co-integrated with B6 and B8 of the core map; therefore they will be referred to as the B6 and B8 linkage groups from herein. One QTL each on B6 and B8 were detected that explained $12 \%$ and $38 \%$ of the phenotypic variation for resistance to white mold in the straw tests, respectively (Table 3 and Fig. 2). As determined by sCIM the QTL on B6 spanned the interval between RAPD markers AU5.1350 and R4.950/1025 (2.9 cM). The QTL on B8 spanned the interval between RAPD markers B10.1100 and AW9.1200 (6.5 cM). The favorable alleles for both QTL were derived from NY6020-4. The same general region spanning $2.6 \mathrm{cM}$ between $\mathrm{A} 8.510$ and $\mathrm{AX6.1000}$ on $\mathrm{B} 6$ detected a QTL that explained 13\% of the phenotypic variation for resistance to white mold in the field; however, 'Benton' contributed the favorable allele for this QTL. A QTL explaining 26\% of the phenotypic variation for resistance to white mold in the field was detected in the same general region of B8, spanning $2.5 \mathrm{cM}$ between AW9.1200 and C7.850.

Flanking the QTL contributing to resistance to white mold on B6, were QTL detected by SIM but not sCIM explaining $20 \%$ of
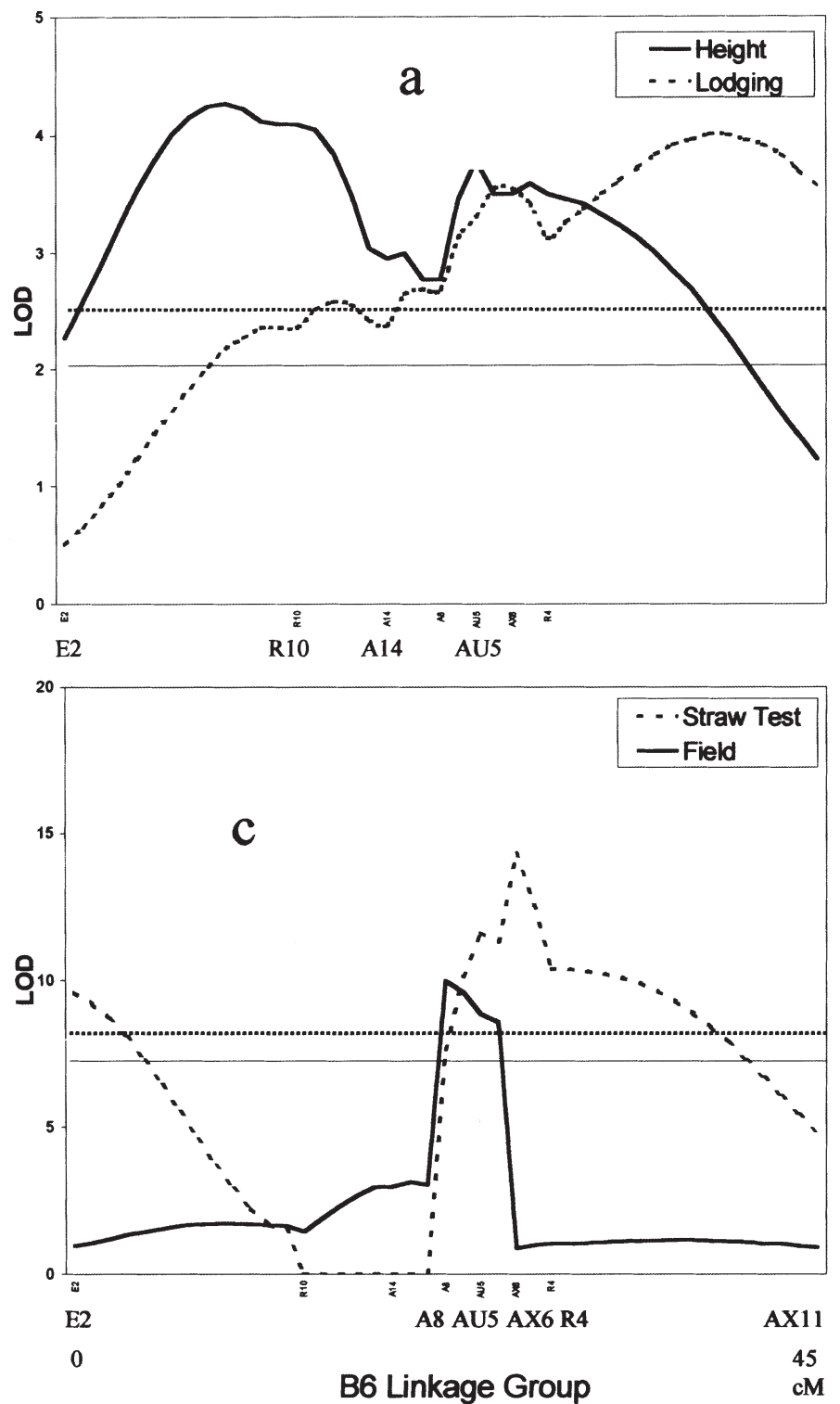

the variation for canopy height (E2.490/550 - A14.1100) and $15 \%$ for lodging (AX6.1000 - AX11.500) (Fig.2 and Table 3). 'Benton' contributed the favorable allele for reduced lodging. The $U r-4$ gene was tightly linked with the A14.1100 marker $(1.3 \mathrm{cM})$ as expected (Miklas et al., 1993), but was even more tightly linked $(0.6 \mathrm{cM})$ with the flanking A8.510 RAPD marker(Fig. 1). This result provides unequivocal evidence for locating $U r-4$ to the B6 linkage group (Miklas et al., 2002). Whether A8.510 has utility for marker-assisted selection (MAS) of $U r-4$ across gene pools is worth testing in lieu of the limited utility of A14.1100 for MAS to just the Middle American gene pool (Miklas et al., 1993). A QTL explaining 26\% of the phenotypic variation for first internode length (AX11.425 -AW9.1200) was detected in a region near the B8 QTL conditioning resistance to white mold in the straw test and field.

Attempts were made to convert the RAPD markers (derived from NY6020-4) flanking the QTL that conditioned resistance to white mold in the straw test on B6 (AU5.1350), and in the straw test and field on B8 (AW9.1200, V14.775, S18.1650), into sequence characterized amplified region (SCAR) markers. SCARs
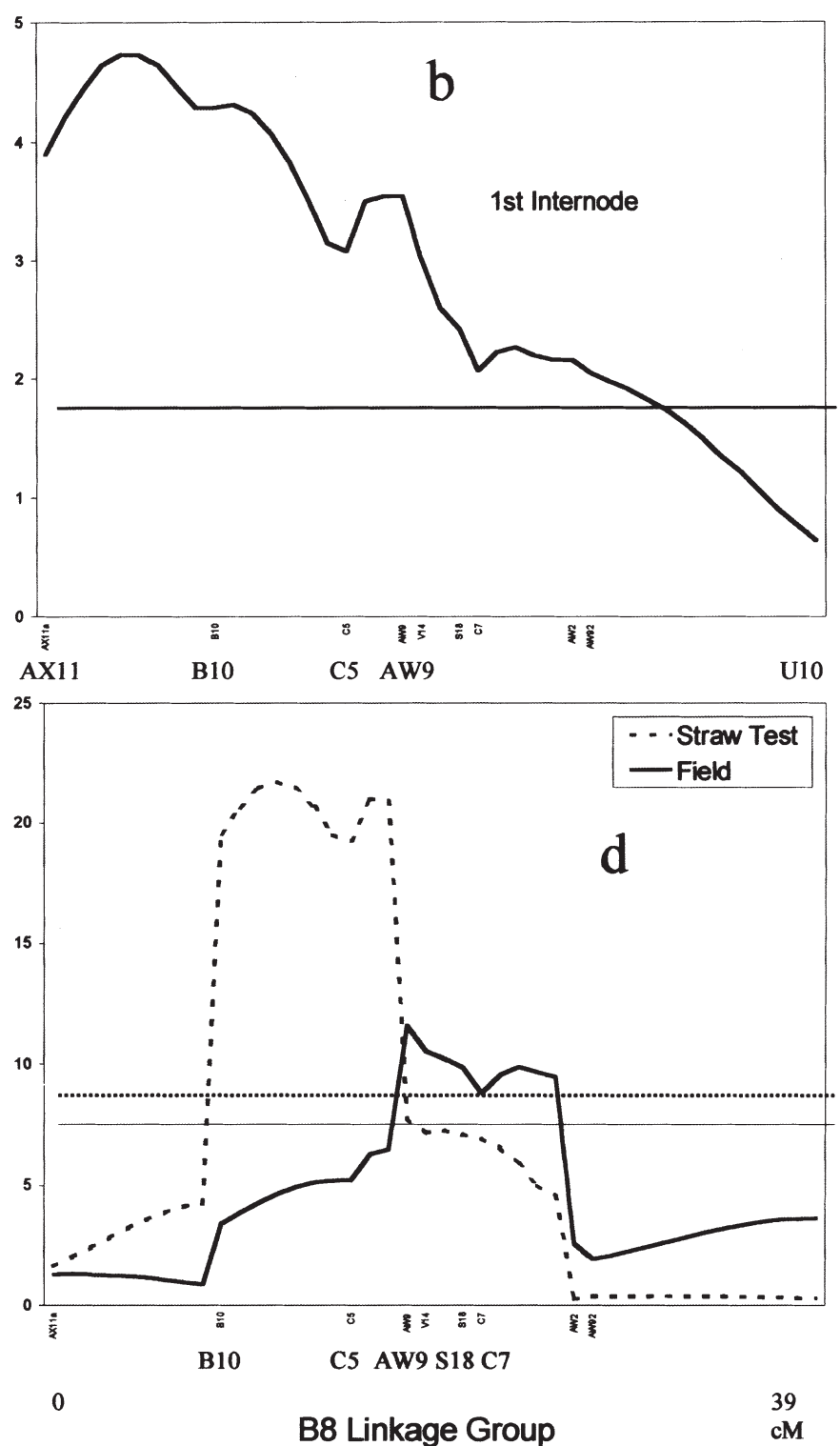

Fig.2. Simple interval mapping (SIM = solid line) for identification of QTL on linkage group B6 for canopy height and lodging (a); B8 for first intenode length (b); and sCIM for identification of QTL on linkage groups B6 (c) and B8 (d) for white mold disease severity in the greenhouse straw test and field. The horizontal line(s) represent the $5 \%$ significance level for each trait based on 1000 permutations. 


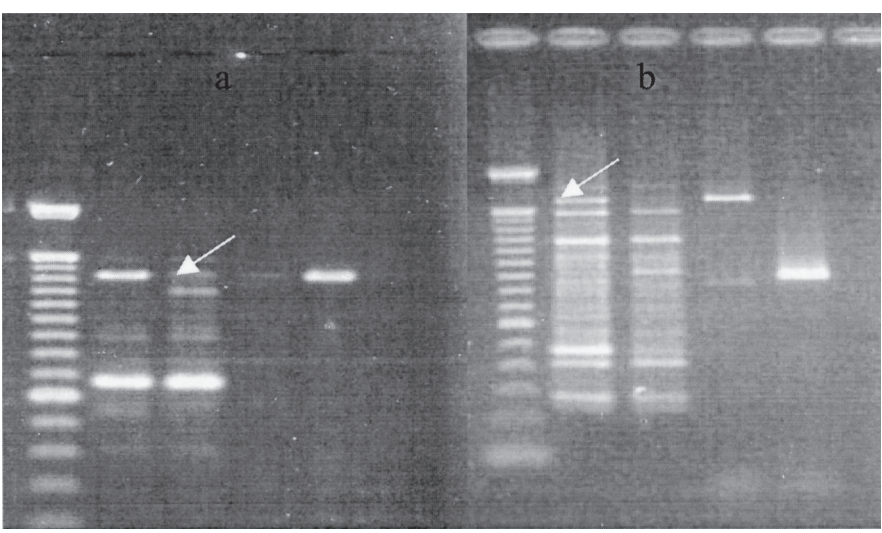

Fig 3. Depiction of the SCAR markers SAU5.1350 (lane 5a, arrow) and SS18.1650 (lane 4b, arrow), derived from corresponding RAPD markers (lanes $2 \mathrm{a}$ and 2b), linked with QTL on linkage groups B6 and B8, respectively, conditioning resistance to white mold in 77 RILs from a cross between 'Benton' and NY6020-4. The forward-AGCTACCGTCAGTTTACTAA and reverseAGCTACCGTGGCTTTTTTCT primers for the SAU5.1350 SCAR, and F-CTGGCGAACTGTACATGCAACATAC and R-CTGGCGAACTGATT CATACATTTTG primers (original decamer primer for generation of the RAPD in bold) for the SS18.1650 SCAR, work best at an annealing temperature of $63{ }^{\circ} \mathrm{C}$. (Note the lower 900 bp monomorphic or codominant bands in lanes $4 \mathrm{~b}$ and $5 \mathrm{~b}$ amplified by SS18 SCAR primers is useful for eliminating false negatives due to a lack of amplification from a faulty PCR reaction). Lanes 1a and $1 \mathrm{~b}=100-\mathrm{bp}$ ladder.

were successfully developed for only the AU5.1350 and S18.1650 RAPD markers; renamed SAU5.1350 and SS18.1650(Fig. 3). These SCARs and the aforementioned RAPDs namely AX6.1000 (B6 QTL) and AW9.1200 (B8 QTL) will facilitate future investigations of the potential for MAS to incorporate and improve white mold resistance in common bean.

The individual QTL on B6 (AU5.1350) and B8 (AW9.1200) derived from NY6020-4 had an additive effect explaining $43 \%$ of the phenotypic variation for disease reaction in the straw test (Table 4). Multiple regression of reaction to white mold in the field $\left(R^{2}=51 \%\right)$ emphasized the contribution of the B6 ('Benton' derived) and B8 (NY6020-4 derived) QTL to the resistance response, and additional contribution of canopy height and lodging to disease avoidance.

\section{Discussion}

Selective mapping of disease reaction in $77 \mathrm{~F}_{57}$ RILs ('Benton'/ NY6020-4) successfully identified QTL conditioning resistance to white mold in the greenhouse and field, further validating the utility of the partial mapping approach for identifying QTL in common bean (Miklas et al., 1996; Kolkman and Kelly, 2003). A common genomic region on B8 (AW9.1200) conditioned low disease score in the straw test and field, suggesting that the same resistance gene(s) (QTL) was expressed in both environments. The QTL was phenotypically correlated and genomically linked with first internode length on B8, indicating that stem morphology influenced expression of resistance in this population.

Although RILs with longer first internodes exhibited less dis- ease in the greenhouse and field tests, they were prone to lodging in the field. Increased lodging would be expected to reduce disease avoidance resulting from an upright and open plant canopy. Thus, the favorable effect first internode length had on increased expression of resistance in the field was tempered somewhat by contributing to increased lodging. Tight linkage between distinct QTL conditioning physiological resistance and internode length may also exist. If such a linkage does exist, then the RILs \# 48, $\# 69$, \#72, and \#80, which possess shorter first internodes in combination with increased resistance in the straw test and field, could represent useful recombinants (data not shown). Using a set of such lines to form the R-DNA pool may have enabled detection of additional QTL conditioning resistance to white mold, but in a more desirable phenotype. Kolkman and Kelly (2003) used such a strategy, termed multi-trait bulking, to selectively map QTL conditioning resistance to white mold in a desirable high yielding phenotype with commercially acceptable maturity.

The QTL on B6 (AU5.1350) conditioning resistance to white mold in the straw test also derived from NY6020-4, but was not expressed in the field, because reduced lodging contributed by 'Benton' mapped to the same genomic region. The influence of reduced lodging on disease avoidance is evident by the inclusion of the 'Benton' allele (selection against AU5.1350) in the model of field reaction (Table 4), and by the correlation of decreased disease severity in the field with decreased lodging (Table 2). 'Benton' has a more compact growth habit that is resistant to lodging. Conversely, lines that lodged less were more susceptible in the straw test. This reversed expression at the B6 QTL region likely contributed to the lack of a correlation between greenhouse and field determination of mean disease reaction. Despite the lack of correlation, expression of the major-effect QTL on B8 across both environments supports previous findings that the straw test can be used to predict resistance to white mold in the field (Hall and Phillips, 1998; Miklas et al., 2001; Myers et al., 1999; Park et al., 2001).

Resistance to white mold in the straw test is thought to be primarily conditioned by physiological mechanisms, however, the restriction of pathogen movement across nodal tissue is well noted (Miklas et al., 1992; Pedzodlt and Dickson, 1996) and suggests that stem morphology contributes to resistance in the straw test. The association of lodging (B6) and internode length (B8) with disease resistance in the 'Benton'/NY6020-4 population confirms the importance of stem morphology in the straw test. Due to the potential for stem morphology to confound expression of physiological resistance, use of additional screening methods may be needed to better define resistance mechanisms present in lines that perform well in the straw test. Steadman et al. (2001) reported that NY6020-5 (sister line) was susceptible in three separate oxalate tests (Kolkman and Kelly, 2000) and moderately resistant in a detached stem test (Steadman et al., 2001), reinforcing that the resistance expressed by NY6020-4 is related to stem morphology and perhaps to other physiological mechanisms that have not been detected or fully understood.

The B8 QTL derived from NY6020-4 maps adjacent to a QTL (Kelly et al., 2003) for resistance to white mold (straw test, field, and plant height) derived from PC 50 (Park et al., 2001), which

Table 4. Multiple regression analyses of disease reaction to white mold in $77 \mathrm{~F}_{5: 7}$ RILs from the cross 'Benton'/NY6020-4.

\begin{tabular}{lcl}
\hline Disease reaction & Model $R^{2}$ & Partial $R^{2}$ components \\
\hline Straw test (1-9) & $43 \%$ & $\mathrm{y}^{\mathrm{z}}=6.55-0.93$ [AW9.1200 B8 QTL (34\%)] - 0.51 [AU5.1350 B6 QTL (9\%)] \\
Field reaction (1-9) & $51 \%$ & $\mathrm{y}^{\mathrm{z}}=6.48-0.93$ [AW9.1200 B8 QTL (26\%)] + 0.51 [AU5.1350 B6 QTL (15\%)] - 0.04 [canopy height \\
& & $(5 \%)]+0.23$ [lodging (3\%)] - 0.16 [first internode (2\%)] \\
\hline
\end{tabular}

${ }^{\mathrm{z}} \mathrm{y}=$ disease reaction from 1 to 9 where $1=$ symptomless and $9=$ completely susceptible. 
suggests that both resistance sources may possess the same QTL. The Co-4 gene for resistance to anthrancose [caused by Colletotrichum lindemuthianum (Sacc. \&Magnus) Lams.-Scrib] and two QTL for resistance to common bacterial blight [caused by Xanthomonas campestris pv. phaseoli (Smith) Dye] map near the QTL for white mold resistance on B8 (Kelly et al., 2003). The Ur-4 rust resistance gene derived from 'Benton' maps in the vicinity of the B6 QTL, and its retention and deployment in new snap bean cultivars is critical. So, as with the B6 QTL and rust resistance, recombination of the B8 QTL with other linked resistance traits may be necessary to develop cultivars possessing certain combinations of multiple disease resistance to white mold, anthracnose, common bacterial blight, and rust.

Results confirm that partial resistance to white mold in the 'Benton'/NY6020-4 RIL population is quantitatively inherited and conditioned by stem morphology, avoidance, and perhaps physiological mechanisms. Although complex, resistance was moderately heritable and conditioned primarily by two QTL expressed across environments. Marker-assisted breeding for these QTL in either early or late generations may be useful because screening for resistance to white mold is difficult for most breeding programs. The NY6020-4 resistance source may not be effective in snap bean, however, until recombination can be established and verified between traits such to confirm presence of the resistance QTL in a commercial phenotype.

\section{Literature Cited}

Dickson, M.H., J.E. Hunter, M.A. Boettger, and J.A. Cigna. 1982. Selection for resistance in Phaseolus vulgaris L. to white mold disease caused by Sclerotinia scleroriorum (Lib.) deBary. J. Amer. Soc. Hort. Sci. 107:231-234.

Doerge, R., and A. Rebai. 1996. Significance thresholds for QTL interval mapping tests. Heredity 76:459-464.

Fehr, W.R. 1987. Principles of cultivar development. vol. 1. Theory and technique. Macmillan, New York.

Freyre, R., P.W. Skroch, V. Geffroy, A.F. Adam-Blondon, A. Shirmohamadali, W.C Johnson, V. Llaca, R.O. Nodari, P.A. Pereira, S.M. Tsai, J. Thome, M. Dron, J. Nienhuis, C.E. Vallejos, and P. Gepts. 1998 Towards an integrated linkage map of common bean. IV. Development of a core linkage map and alignment of RFLP maps. Theor. Appl. Genet. 97:847-856.

Fuller, P.A., D.P. Coyne, and J.R. Steadman. 1984. Inheritance of resistance to white mold disease in a diallel cross of dry beans. Crop Sci. 24:929-933.

Hall, R. and L.G. Phillips. 1998. Field evaluation of the straw test for assessing resistance of dry bean to white mold. Annu. Rpt. Bean Improv. Coop. 41:171-172.

Hang, A.N., M.J. Silbernagel, P.N. Miklas, and G.L. Hosfield. 1998 Registration of 'Burke' Pinto bean. Crop Sci. 38:885.

Kelly, J.D., P. Gepts, P.N. Miklas, and D.P. Coyne. 2003. Tagging and mapping of genes and QTL and molecular marker-assisted selection for traits of economic importance in bean and cowpea. Field Crops Res. (in press).

Kelly, J.D., J.R. Stavely, and P.N. Miklas. 1996. Proposed symbols for rust resistance genes in common bean. Annu. Rpt. Bean Improv. Coop. 39:25-31.

Knapp, S.J., W.W. Stroup, and W.M. Ross. 1985. Exact confidence inter- vals for heritability on a progeny mean basis. Crop Sci. 25:192-194. Kolkman, J.M. and J.D. Kelly. 2000. An indirect test using oxalate to determine physiological resistance to white mold in common bean. Crop Sci. 40:281-285

Kolkman, J.M. and J.D. Kelly. 2002. Agronomic traits affecting resistance to white mold in common bean. Crop Sci. 42:693-699.

Kolkman, J.M. and J.D. Kelly. 2003. QTL conferring resistance and avoidance to white mold in common bean. Crop Sci. 43:539-548.

Kosambi, D.D. 1944. The estimation of map distances from recombination values. Ann. Eugen. 12:172-175.

Lander, E.S., P. Green, J. Abrahamson, A. Barlow, M.J. Daley, S.E. Lincoln, and L. Newburg. 1987. MAPMAKER: An interactive computer package for constructing primary genetic linkage maps of experimental and natural populations. Genomics 1:174-181.

Lyons, M.E., M.H. Dickson, and J.E. Hunter. 1987. Recurrent selection for resistance to white mold in Phaseolus species. J. Amer. Soc. Hort. Sci. 112:149-152.

Miklas, P.N. 2001. Bean white mold disease screening results for 2000 and 2001. http://www.usda.prosser.wsu.edu/wht_mold_ Pat2000htm.htm).

Miklas, P.N., R. Delorme, R. Hannan, and M.H. Dickson. 1999. Using a subsample of the core collection to identify new sources of resistance to white mold in common bean. Crop Sci. 39:569-573.

Miklas, P.N. and K.F. Grafton. 1992. Inheritance of partial resistance to white mold in inbred populations of dry bean. Crop Sci. 32:943-948.

Miklas, P.N., K.F. Grafton, and B.D. Nelson. 1992. Screening for partial physiological resistance to white mold in dry bean using excised stems. J. Amer. Soc. Hort. Sci. 117:321-327.

Miklas, P.N., E. Johnson, V. Stone, J.S. Beaver, C. Montoya, and M. Zapata. 1996. Selective mapping of QTL conditioning disease resistance in common bean. Crop Sci. 36:1344-1351.

Miklas, P.N., W.C. Johnson, R. Delorme, and P. Gepts. 2001. QTL conditioning physiological resistance and avoidance to white mold in dry bean. Crop Sci. 41:309-315.

Miklas, P.N., M.A. Pastor-Corrales, G. Jung, D.P. Coyne, J.D. Kelly, P.E. McClean, and P. Gepts. 2002. Comprehensive linkage map of bean rust resistance genes. Annu. Rpt. Bean Improv. Coop. 45:125-129.

Miklas, P.N., J.R. Stavely, and J.D. Kelly. 1993. Identification and potential use of a molecular marker for rust resistance in common bean. Theor. Appl. Genet. 85:745-749.

Myers, J.R., B. Gilmore, and D. Kean. 1999. Correlation between the field and straw test for white mold resistance in common bean. Annu. Rpt. Bean Improv. Coop. 42:57-58.

Park, S.O., D.P. Coyne, J.R. Steadman, and P.W. Skroch. 2001. Mapping of QTL for resistance to white mold disease in common bean. Crop Sci. 41:1253-1262.

Petzoldt, R. and M.H. Dickson. 1996. Straw test for resistance to white mold in beans. Annu. Rpt. Bean Improv. Coop. 39:142-143.

SAS Institute. 1987. SAS/STAT guide for personal computers, 6th ed. SAS Inst., Cary, N.C.

Steadman, J., K. Eskridge, J. Costa, K. Grafton, J. Kelly, K. Kmiecik, J. Kolkman, J. Myers, and P. Miklas. 2001. Evaluation of sources of resistance to Sclerotinia sclerotiorum in common bean with five test methods at multiple locations. Annu. Rpt. Bean Improv. Coop. 44 89-90

Steel, R.G.D. and J.H. Torrie. 1980. Principles and procedures of statistics. McGraw-Hill, New York.

Tinker, N.A. and D.E. Mather. 1995. MQTL: software for simplified composite interval mapping of QTL in multiple environments. JQTL 1995-02. 